\title{
In-silico studies of Neurocognitive and Neuropharmacological effect of Bacopa monnieri (L.)
}

Satyam Sangeet ${ }^{*}+1$, Arshad Khan ${ }^{2}$

${ }^{1}$ Indian Institute of Science Education and Research (IISER), Bhopal, Madhya Pradesh, India

${ }^{2}$ National Institute of Technology (NIT), Arunachal Pradesh, India

\section{Present Address}

†Indian Institute of Science Education and Research (IISER), Kolkata, West Bengal, India

*Corresponding author - Satyam Sangeet, Department of Chemistry, Indian Institute of Science Education and Research (IISER), Kolkata, West Bengal, India

satyam_verma0@yahoo.in (+91-7028510659) 


\section{ABSTRACT}

Different Indian therapeutic plants have picked up consideration for their restorative properties against neurodevelopmental disorders lately. Bacopa monnieri (B. monnieri), being one of them, finds its utilization significantly in the treatment of cognition and learning. Despite the fact that it possesses such great capacity to treat neurological issues, how precisely it confers its influence is muddled. This study makes a stride towards knowing which phytochemical is significantly associated with granting B. monnieri with therapeutic properties. The docking investigation and the molecular simulation studies proposes that there is no single phytochemical included that imparts B. monnieri a significant medicinal effect. It is really the blend of dominant part of natural phytochemicals present in $B$. monnieri that bestows the anti-neurological activity to $B$. monnieri. The ADME studies shows the convergence of properties of phytochemicals of B. monnieri with that of commercially available drugs which suggests that phytochemicals of B. monnieri can used as a potential drug source to treat neurodegenerative and neurodevelopmental disorders.

Keywords: Neurotrophins, Bacopa monnieri, Docking, Molecular simulations, ADME, Phytochemicals 


\section{INTRODUCTION}

Neurodegenerative disorders (NDs) are recognized to be noteworthy threats to human health. Numerous symptoms are associated with NDs including memory loss, tremors, forgetfulness, agitation. Many kinds of mechanism lead to NDs such as apoptosis, protein aggregation, oxidative stress, excitotoxicity and ageing. NDs constitute various types of disorders which include Parkinson's ${ }^{1}$, Huntington's ${ }^{2}$ Alzheimer's disease and other dementias ${ }^{3}$, amyotrophic lateral sclerosis ${ }^{4}$, frontotemporal dementia ${ }^{5}$, spinocerebellar ataxias ${ }^{6}$, stroke $^{7}$, meningitis $^{8}$, encephalitis ${ }^{9}$, tetanus ${ }^{10}$, epilepsy ${ }^{11}$, multiple sclerosis ${ }^{12}$, motor neuron disease $^{13}$, migraine $^{14}$, tension-type headache ${ }^{15}$, medication overuse headache ${ }^{16}$, brain and nervous system cancers ${ }^{17}$, and a residual category of other neurological disorders. There is huge burden of NDs on the global, regional and national levels. Vast number of people have been affected by these diseases. Global burden of NDs are estimated to be around 450 million $^{18}$.

The NDs have a major involvement of Neurotrophins, which are group of proteins having related structures and functions and have an important involvement in survival ${ }^{19,20}$, maintenance ${ }^{21}$, function ${ }^{22,23}$ regulation $^{24}$ and development ${ }^{25}$ of neurons. The mammalian cells include four types of Neurotrophins: Brain-derived Neurotrophic Factor (BDNF) ${ }^{26}$, Neurotrophin 4 (NT 4/5) ${ }^{27}$, Nerve Growth Factor (NGF) ${ }^{28}$ and Neurotrophin 3 $(\mathrm{NT}-3)^{29}$. Neurotrophins belong to a class of growth factors hence named as neurotrophic factors ${ }^{30}$. Neurotrophic factors that mammalian cells secrete plays an important role in the survival of neurons by preventing them from participating in programmed cell death. Decrease in the level of Neurotrophins results in several neurodegenerative disorder ${ }^{31,32}$. Several studies have considered Neurotrophins to be a potential target for the treatment of neurological disorders $33,34,35$.

All the four Neurotrophins bind individually, by same affinity with their common receptor P75 ${ }^{\mathrm{NTR}} 36$ and a specific trk receptor kinase, and thus activates the signal cascade response. $\mathrm{p} 75^{\mathrm{NTR}}$ receptor is structurally related to the tumour necrosis factor receptors (p55 $5^{\mathrm{TNFR}}$ and $\mathrm{p} 75^{\mathrm{TNFR}}$ ). In NGF, residues Lys32, Lys34 and Lys95 have been found to be actively associated with the p75NTR binding. Also, the involvement of residues Trp21, Asp30, Ile31, Glu35, Lys88, Arg100 and Arg103 with the binding of p75NTR has been reported ${ }^{37}$. 
Several synthetic drugs are being used to treat different neurological disorders ${ }^{38}$, for example, Multiple Sclerosis (MS) a neurological disease is treated by wide arrays of repurposed drugs. Some drugs which proved to be effective in mitigating the effect of MS are mitoxantrone ${ }^{39}$, cyclophosphamide ${ }^{40}$, cladribine $^{41}$, amiloride ${ }^{42}$ and ibudilast $^{43}$. Use of synthetic drugs is being restricted because of their various kind of side effects such as headache, pain, toxicity, nausea, alopecia, male and women infertility and risk of malignancy. Mitoxantrone is reported to impart many kinds of side effects in the patient suffering from $\mathrm{MS}^{44}$. Cyclophosphamide and cladribine also have shown significant side effects ${ }^{45}$.

Various components of medicinal plants are known to have therapeutic effects pertaining to neurodegenerative disorders ${ }^{46}$.It is revealed that different metabolites present in plants such as phenolics, isoprenoids and alkaloids etc. are mainly responsible for neurotherapeutic actions. Several traditional plants such as Indian traditional plants (Plants of Ayurveda), Chinese traditional plants, Utopian traditional plants and Persian traditional plants etc. have been reported widely to heal brain disorders and diseases of nervous system. Some example of the traditional plants used against neurodegenerative disorders are Curcuma longa $\mathrm{L}^{47}$, Murraya koenigii (L.) Spreng ${ }^{48}$, Cassia obtisufolia L. ${ }^{49}$, Sanguisorba officinalis L. ${ }^{50}$, Rosmarinus officinalis L.

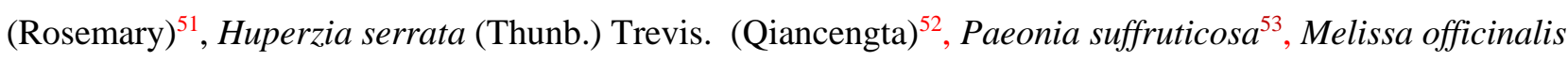
L. ${ }^{54}$.

Phytochemicals from medicinal plants have been exploited for their potential in targeting neurodegenerative disorders by regulating the Neurotrophins. Example of some plants whose phytochemicals target NDs by affecting Neurotrophins are Aster scaber ${ }^{55}$, Camellia sinensis ${ }^{56}$, Curcuma longa $^{57}$, Ginkgo biloba (L) ${ }^{58}$, Liriope platyphylla $^{59}$ and Magnolia officinalis ${ }^{60}$.

Bacopa monnieri $(\mathrm{BM})$ is a significant Ayurvedic medicinal plants that has been in use since ancient time to enhance brain function and to improve intelligence as well as memory ${ }^{61}$. Role of B. monnieri in cognitive and memory enhancement has been studied extensively ${ }^{62}$. B. monnieri contains many bioactive components such as saponins, triterpenoid bacosaponins and saponin glycosides ${ }^{62}$. Stough et $\mathrm{l}^{63}$ reported that B. monnieri extract enhanced the cognition safely and effectively. Standard extracts of B. monnieri have shown 
improvement in many neurodegenerative disorders owing to presence of different bioactive phytochemicals $^{60,63,64,65,66}$

Treatment of neurodegenerative disorders by targeting Neurotrophins using the plant extract of Bacopa monnieri $(\mathrm{BM})$ has not been reported yet. $\mathrm{Lal} \& \mathrm{Lal}^{67}$ has reported phytochemicals present in the plant extract of BM using GC-MS study. Even, with the advancement in technology, it is still not clear as to how BM imparts its effect on the ND. Also, the molecular pathway behind the action is not clearly understood.

Thus, the current study focuses on the individual activity of $B$. monnieri phytochemicals against the Neurotrophins by studying its molecular docking analysis and molecular simulations. This study will provide us with an insight as to which phytochemical is majorly involved in imparting $B$. monnieri its medicinal property and whether the neuroprotective activity of $B$. monnieri is due to a single phytochemical or a cumulative effect of all the phytochemicals combined.

\section{MATERIALS AND METHOD}

\section{Ligand and Receptor Preparation}

The approved drugs for the treatment of Multiple Sclerosis (Cladribine, Cyclophosphamide and Mitoxantrone) were chosen as the standard drugs ${ }^{38}$. Based on the literature evidences ${ }^{67}$, the structure of 26 phytochemicals of $B$. monnieri (Table 1) were downloaded from PubChem (https://pubchem.ncbi.nlm.nih.gov/) database ${ }^{68}$. The phytochemicals were converted from 2D to 3D by using Open Babel software ${ }^{69}$ and were energy minimized using Chem $3 \mathrm{D}^{70}$ software using MM2 minimize.

Receptor PDB structures of Brain-Derived Neurotrophic Factor (PDB ID: 1BND), Neurotrophin 3 (PDB ID: 1B8K), Neurotrophin 4 (PDB ID: 1B98) and Nerve Growth Factor (PDB ID: 4EDX) were downloaded from Protein Data Bank (www.rcsb.org). The receptors were prepared by deleting all the water molecules and unwanted residues and energy minimizing it using Chimera software ${ }^{71}$. 


\section{Molecular Docking}

PatchDock online server (https://bioinfo3d.cs.tau.ac.il/PatchDock/) was employed for the molecular docking studies between the Neurotrophins and the phytochemicals. The clustering RMSD values were set at default (4.0 ̊) as suggested by the server. The respective Neurotrophin structures were uploaded in the Receptor molecule option and the phytochemical structures were uploaded in the Ligand Molecule option. The PatchDock score and the ACE value were tabulated and the result was visualized in Discovery studio ${ }^{72}$.

\section{Molecular Simulation}

The online server CABS-flex 2.0 (http://biocomp.chem.uw.edu.pl/CABSflex2) was utilized for the molecular simulations of the docked results. The values were set as the default parameter as suggested by the server. The results obtained were downloaded in the form of excel sheet. The Root Mean Square Fluctuation (RMSF) curves were visualized using Jupyter Notebook and matplotlib python package.

\section{ADME Studies}

Adsorption, Digestion, Metabolism, Excretion and Toxicity studies were performed using SWISSADME server (http://www.swissadme.ch; ${ }^{73}$ ). The structure of drugs and phytochemicals were uploaded and the corresponding drug likeness features such as lipophilicity, solubility and drug likeness score were obtained.

Table 1. Phytochemicals and commercial drugs and their structure

\section{Phytochemical Name}

\section{Phytochemical Structure}

1,2-Benzenedicarboxylic acid, mono(2-ethylhexyl) ester

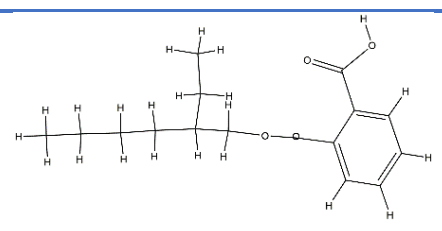

2,6,10-Trimethyl,14-ethylene-14-Pentadecne

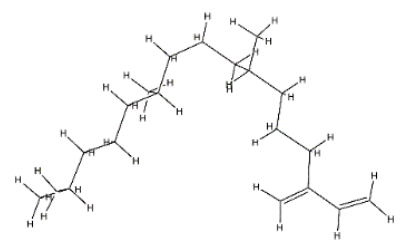


2-Cyclohexen-1-one,3-(3-hydroxybutyl)-2,4,4trimethyl-

2-Cyclohexen-1-one, 4-hydroxy-3,5,5-trimethyl-4-(3oxo-

1-butenyl)-

2-Nonenal, 2-Pentyl-

2-Pentadecanone, 6,10,14-Trimethyl-

3,7,11,15-tetramethyl-2-Hexadecen-1-ol

3A(1H)-Azulenol,2,3,4,5,8,8A-hexahydro-6,8Adimethyl-

3-(1-M

9-Octadecenoic acid (Z)-

17-(1,5-Dimethyl-hex-2-enyl)-10,13-

dimethyl2,3,4,9,10,11,12,13
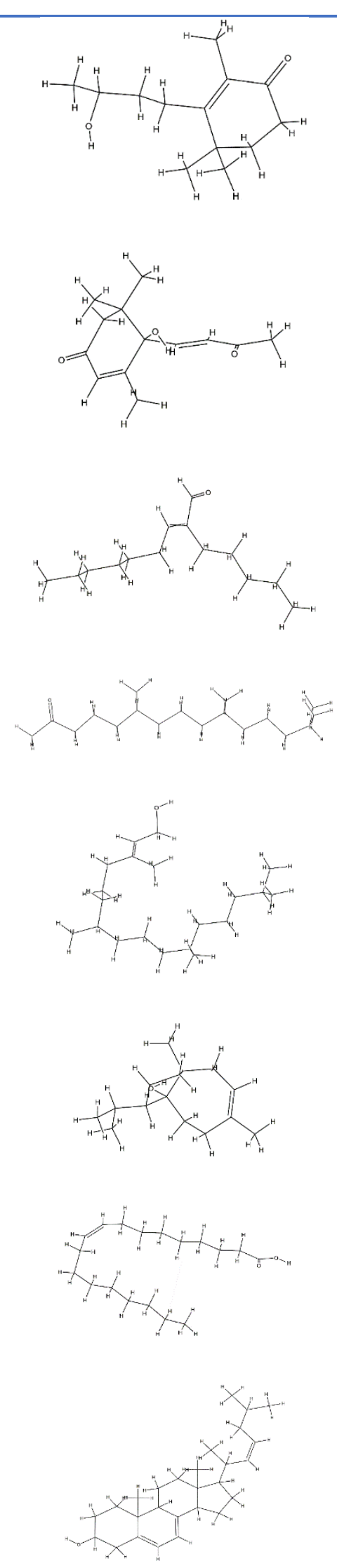
Benzenepropanoic acid, 3,5-bis(1,1-dimethylethyl)-

4hydroxy-, methyl ester

Cis-9-Hexadecenal

Cis-10-Nonadecenoic acid

Dodecane

Heneicosane

Hexadecanoic acid, 2-hydroxy-1-(hydroxymethyl)ethyl

ester

Hexadecanoic acid, methyl ester

Icosanoic acid

Nonacosane

Octadecanoic acid
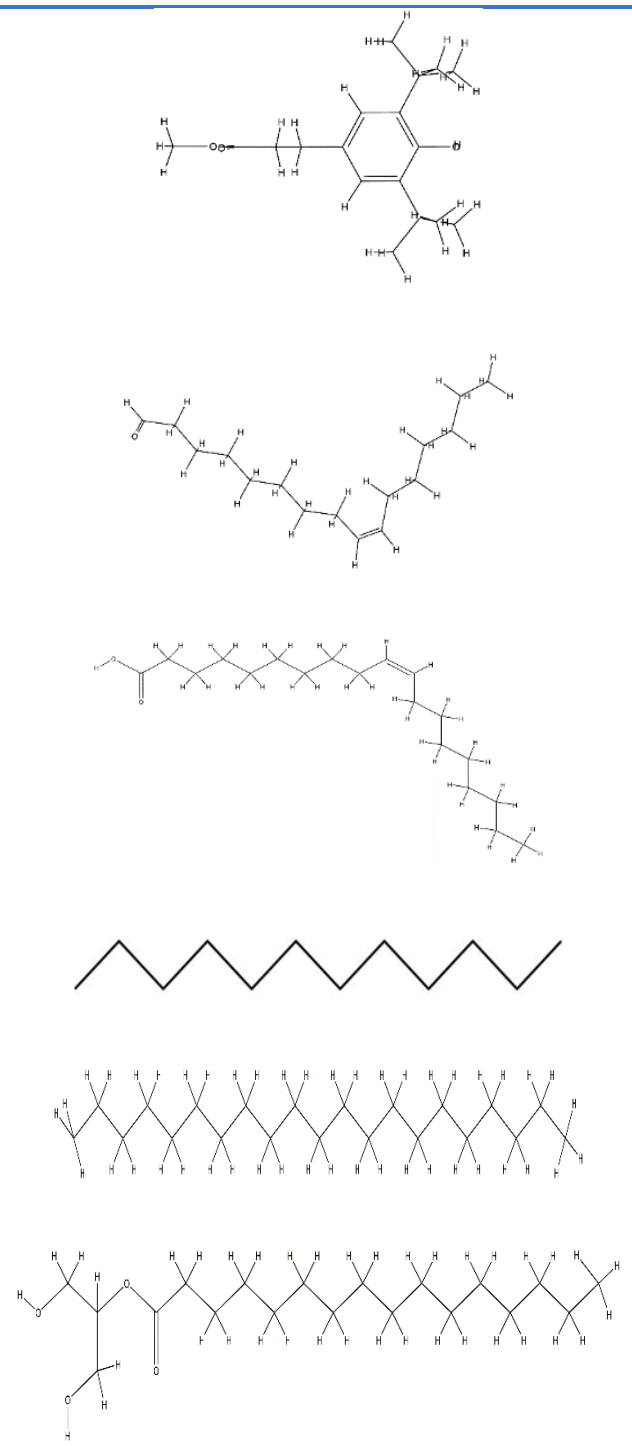
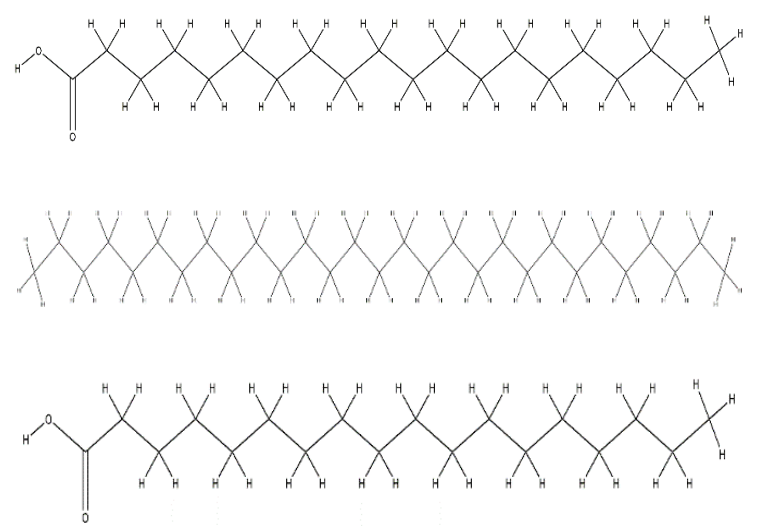
bioRxiv preprint doi: https://doi.org/10.1101/2021.01.20.427542; this version posted January 21, 2021. The copyright holder for this preprint (which was not certified by peer review) is the author/funder. All rights reserved. No reuse allowed without permission.

Octadecanoic acid, ethyl ester

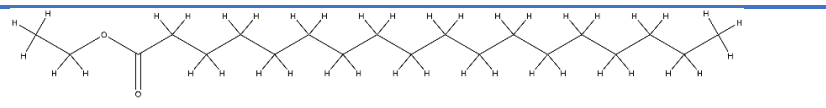

Phenol, 2-methoxy-4-(2-Propenyl)

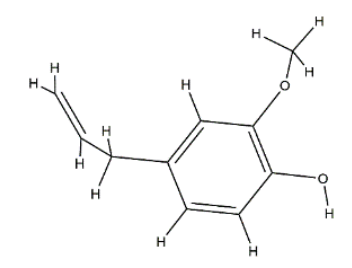

Phytol

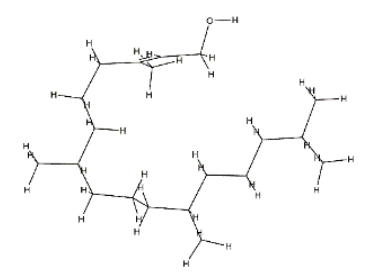

Stigmasterol

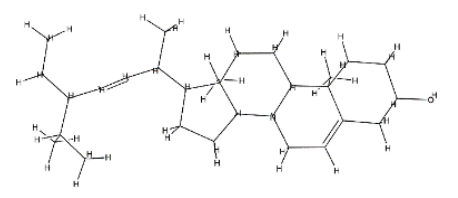

Tridecane

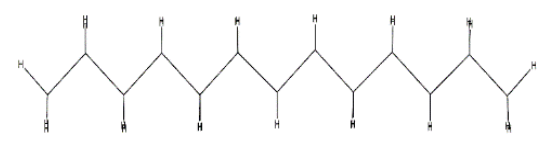

Vitamin E

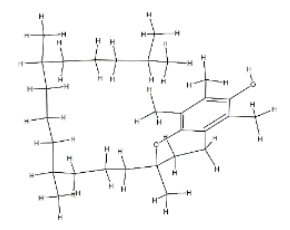

\section{Cladribine}<smiles>Nc1nc(Cl)nc2c1ncn2[C@H]1C[C@H](O)[C@@H](CO)O1</smiles>

Cyclophosphamide

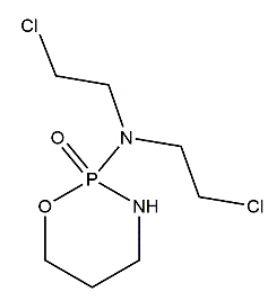




\section{Mitoxantrone}

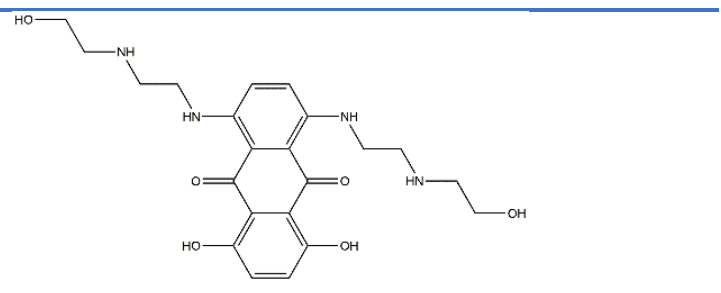

\section{RESULTS}

The molecular docking between the Neurotrophins and the phytochemicals of Bacopa monnieri (B. monnieri) was carried out. Literature studies ${ }^{68}$ were looked for creating the phytochemical database. Once the docking process was finished the molecular simulations were carried out to find the RMSF values of the involved amino acids followed by the ADME studies to see the drug likeness of the phytochemicals.

\section{Computational Docking}

Out of the 26 phytochemicals docked against the four Neurotrophins, only two of them showed interactions with BDNF, two of them showed interaction with Neurotrophin 3, 17 of them showed interaction with Neurotrophin 4 and 11 of them showed interactions with NGF (Table 2).

Table 2. Neurotrophins along with the interacting phytochemicals and the respective PatchDock Score, ACE value and the interacting amino acid residues.

\begin{tabular}{|c|c|c|c|c|}
\hline Neurotrophins & Phytochemicals & PatchDock Score & ACE (kcal/mol) & Interacting Residues \\
\hline BDNF & $\begin{array}{l}\text { 3,7,11,15-tetramethyl- } \\
\text { 2-Hexadecen-1-ol }\end{array}$ & 4108 & -192.86 & $\begin{array}{l}\text { Trp19, Tyr52, Arg88, } \\
\text { Leu49 }\end{array}$ \\
\hline BDNF & Vitamin E & 4592 & -246.62 & $\begin{array}{l}\text { Trp19, Val42, Tyr52, } \\
\text { Phe53, Val87, Arg88, } \\
\text { Trp100 }\end{array}$ \\
\hline $\mathrm{N} 3$ & $\begin{array}{l}\text { Benzene propanoic } \\
\text { acid, 3,5-bis (1,1- } \\
\text { dimethylethyl)- }\end{array}$ & 3630 & -26.71 & Asp105, Glu54 \\
\hline
\end{tabular}


4hydroxy-, methyl ester

N3

N4

N4

N4

N4

N4

N4

2-Pentadecanone,

4890

6,10,14-Trimethyl-

2890

Azulenol,2,3,4,5,8,8Ahe

xahydro-

6,8Adimethyl-3-(1-M

1,2-

4636

Benzene dicarboxylic

acid,

mono (2-

ethylhexyl) ester

$2,6,10-$

5550

Trimethyl,14ethylene-

14Pentadecne

2-Cyclohexen-1-one,

4150

4hydroxy-

3,5,5-trimethyl- 4-

(3oxo-1-butenyl)-

2-Cyclohexen-1-one, 3- 3974

(3-hydroxybutyl)-

2,4,4trimethyl-

2-Nonenal, 2-Pentyl- 4566
$-36.87$

$-201.71$

$-213.87$

$-203.02$

$-175.74$

$-188.57$

$-200.07$ 
bioRxiv preprint doi: https://doi.org/10.1101/2021.01.20.427542; this version posted January 21, 2021. The copyright holder for this preprint (which was not certified by peer review) is the author/funder. All rights reserved. No reuse allowed without permission.

\begin{tabular}{|c|c|c|c|c|}
\hline \multirow[t]{3}{*}{$\mathrm{N} 4$} & 3,7,11,15-tetramethyl2- & 5432 & -286.35 & Phe56, Val97, Trp112, \\
\hline & \multicolumn{3}{|l|}{ Hexadecen-1-ol } & Arg98, Trp110, Gln54, \\
\hline & & & & Ala47, Val44 \\
\hline \multirow[t]{4}{*}{$\mathrm{N} 4$} & $3 \mathrm{~A}(1 \mathrm{H})-$ & 4016 & -215.66 & Val97, Arg98, Trp110, \\
\hline & \multicolumn{3}{|l|}{ Azulenol,2,3,4,5,8,8Ahe } & Val44 \\
\hline & \multicolumn{4}{|l|}{ xahydro- } \\
\hline & \multicolumn{4}{|l|}{ 6,8Adimethyl-3-(1-M } \\
\hline \multirow[t]{2}{*}{ N4 } & 9-Octadecenoic acid & 5398 & -265.53 & Val97, Phe56, Arg98, \\
\hline & $(\mathrm{Z})-$ & & & Trp110, Ala47 \\
\hline \multirow[t]{4}{*}{$\mathrm{N} 4$} & Benzenepropanoic acid, & 4746 & -228.88 & Leu52, Trp110, Arg98 \\
\hline & \multicolumn{4}{|l|}{3,5 -bis $(1,1-$} \\
\hline & \multicolumn{4}{|l|}{ dimethylethyl)- } \\
\hline & \multicolumn{4}{|l|}{ 4hydroxy-, methyl ester } \\
\hline \multirow[t]{2}{*}{ N4 } & Cis-9-Hexadecenal & 5076 & -183.13 & Arg98, Trp110, Leu52, \\
\hline & & & & Val44 \\
\hline \multirow[t]{4}{*}{$\mathrm{N} 4$} & Cis-10-Nonadecenoic & 4750 & -294.98 & Phe56, Val97, Arg98, \\
\hline & acid & & & Trp112, Val44, Trp110, \\
\hline & & & & Ala47, Ala46, Pro45, \\
\hline & & & & Val44 \\
\hline \multirow[t]{2}{*}{$\mathrm{N} 4$} & Dodecane & 4098 & -179.79 & Trp110, Val97, Phe56, \\
\hline & & & & Val44, Ala47, Arg98 \\
\hline \multirow[t]{2}{*}{ N4 } & Phenol, 2-methoxy-4- & 3730 & -137.88 & Tyr55, Arg98, Trp110 \\
\hline & (2-Propenyl)- & & & \\
\hline \multirow[t]{2}{*}{ N4 } & Phytol & 5550 & -312.72 & Phe56, Val97, Arg98, \\
\hline & & & & Trp110, Ala47, Val44 \\
\hline
\end{tabular}




\begin{tabular}{|c|c|c|c|c|}
\hline N4 & Tridecane & 4432 & -173.83 & $\begin{array}{l}\text { Trp110, Ala47, Val44, } \\
\text { Phe56, Arg98, Trp112 }\end{array}$ \\
\hline N4 & Stigmasterol & 5684 & -409.31 & $\begin{array}{l}\text { Ala47, Val44, Trp110, } \\
\text { Arg98, Val97, Phe56, } \\
\text { Trp112 }\end{array}$ \\
\hline NGF & 2-Nonenal, 2-Pentyl- & 3996 & -126.33 & $\begin{array}{l}\text { His84, Thr83, Val109, } \\
\text { Ser17 }\end{array}$ \\
\hline NGF & $\begin{array}{l}\text { 2-Pentadecanone, } \\
\text { 6,10,14-Trimethyl- }\end{array}$ & 4056 & -25.16 & $\begin{array}{l}\text { Phe49, Ala98, Arg100, } \\
\text { Phe101, Trp21, Gln96 }\end{array}$ \\
\hline NGF & Cis-9-Hexadecenal & 3930 & -104.84 & $\begin{array}{l}\text { Phe49, Ala98, Arg100, } \\
\text { Phe101, Ile31, Trp21 }\end{array}$ \\
\hline NGF & Heneicosane & 5136 & -147.24 & $\begin{array}{l}\text { Leu39, Met37, Met92, } \\
\text { Gly94, Lys95 }\end{array}$ \\
\hline NGF & $\begin{array}{l}\text { Hexadecanoic acid, } \\
\text { 2hydroxy-1- } \\
\text { (hydroxymethyl)ethyl } \\
\text { ester }\end{array}$ & 4734 & -93.22 & $\begin{array}{l}\text { Phe101, Arg100, Ala98, } \\
\text { Gln96 }\end{array}$ \\
\hline NGF & $\begin{array}{l}\text { Hexadecanoic acid, } \\
\text { methyl ester }\end{array}$ & 4372 & -64.23 & $\begin{array}{l}\text { Phe49, Phe101, Arg100, } \\
\text { Ala98, Gln96 }\end{array}$ \\
\hline NGF & Nonacosane & 5736 & -171.43 & $\begin{array}{l}\text { Ala98, Lys82, Ile31, } \\
\text { Phe54, Trp21, Ser19, } \\
\text { Val18, Arg69 }\end{array}$ \\
\hline NGF & Octadecanoic acid & 4438 & -145.41 & $\begin{array}{l}\text { Gly40, Leu39, Met37, } \\
\text { Met92, Lys95 }\end{array}$ \\
\hline NGF & $\begin{array}{l}\text { Octadecanoic } \\
\text { ethyl ester }\end{array}$ & 4896 & -156.76 & $\begin{array}{l}\text { Lys95, Met92, Met37, } \\
\text { Leu39, Asp24, Gly23 }\end{array}$ \\
\hline
\end{tabular}




\begin{tabular}{|c|c|c|c|c|}
\hline NGF & Tridecane & 4782 & -337.63 & $\begin{array}{l}\text { Phe101, Arg100, Ala98, } \\
\text { Gln96 }\end{array}$ \\
\hline NGF & Vitamin E & 4636 & -203.65 & $\begin{array}{l}\text { Arg103, His84, Phe86, } \\
\text { Val109, Val111, Phe54, } \\
\text { Ser19, Ser17 }\end{array}$ \\
\hline
\end{tabular}

\section{Brain - Derived Neurotrophic factor (BDNF)}

BDNF naturally interacts with p75 ${ }^{\mathrm{NTR}}$ with residues Gln84, Arg104, Asp30, Arg101, Arg88, Asp93, Lys95, Arg97 and Lys96 ${ }^{36}$. Docking between BDNF and the phytochemicals of Bacopa monnieri showed that only two of the 26 natural phytochemicals show a feasible interaction (Table 2). 3,7,11,15-tetramethyl2Hexadecen1-ol showed hydrogen bonding with Arg88 and hydrophobic interactions with Trp19, Leu49 and Tyr52 with a docking score of 4,108 and an ACE value of -192.86 kcal/mol (Figure 1a). Vitamin E showed hydrophobic interactions with Trp19, Val42, Tyr52, Phe53, Val87, Arg88 and Trp100 with a docking score of 4,592 and an ACE of $-246.62 \mathrm{kcal} / \mathrm{mol}$ (Figure 1b). Thus, this investigation shows that when the phytochemicals of Bacopa monnieri is used as an anti-inflammatory agent against the neurodegenerative disorders, the interaction of phytochemicals with BDNF shows the involvement of two phytochemicals: 3,7,11,15-tetramethyl-2-

Hexadecen-1-ol and Vitamin E.
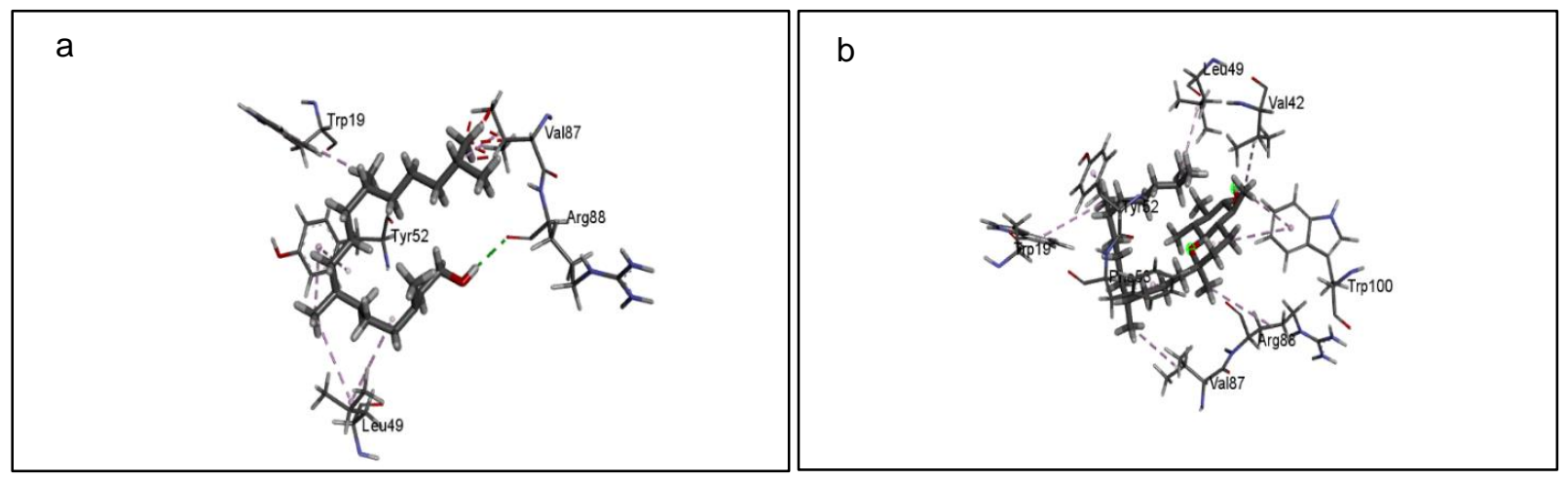

Figure 1. Docking interactions between BDNF and (a) 3,7,11,15-tetramethyl-2-Hexadecen-1-ol (b) Vitamin E 


\section{Neurotrophin 3 (N3)}

Neurotrophin 3 interacts with p75NTR through residues Arg103, Gln83, Asp29, Arg87, His33, Arg31, Arg100, Glu92, Leu96 and Lys95 ${ }^{36}$. Two phytochemicals from B. monnieri interacted with Neurotrophin 3 which are shown in Table 2. Benzene propanoic acid, 3,5-bis(1,1-dimethylethyl)-4hydroxy-, methyl ester showed hydrogen bonding with Asp105 and a carbon hydrogen bonding with Glu54 with a docking score of 3,630 and an ACE value of -26.71 kcal/mol (Figure 2a). 3A(1H)-Azulenol,2,3,4,5,8,8Ahexahydro6,8Adimethyl-3-(1-M showed hydrogen bonding with Gln83 an Arg103. It also showed hydrophobic interactions with Ala27 and Ile104 with a docking score of 2,890 and an ACE value of $-36.87 \mathrm{kcal} / \mathrm{mol}$ (Figure 2b).
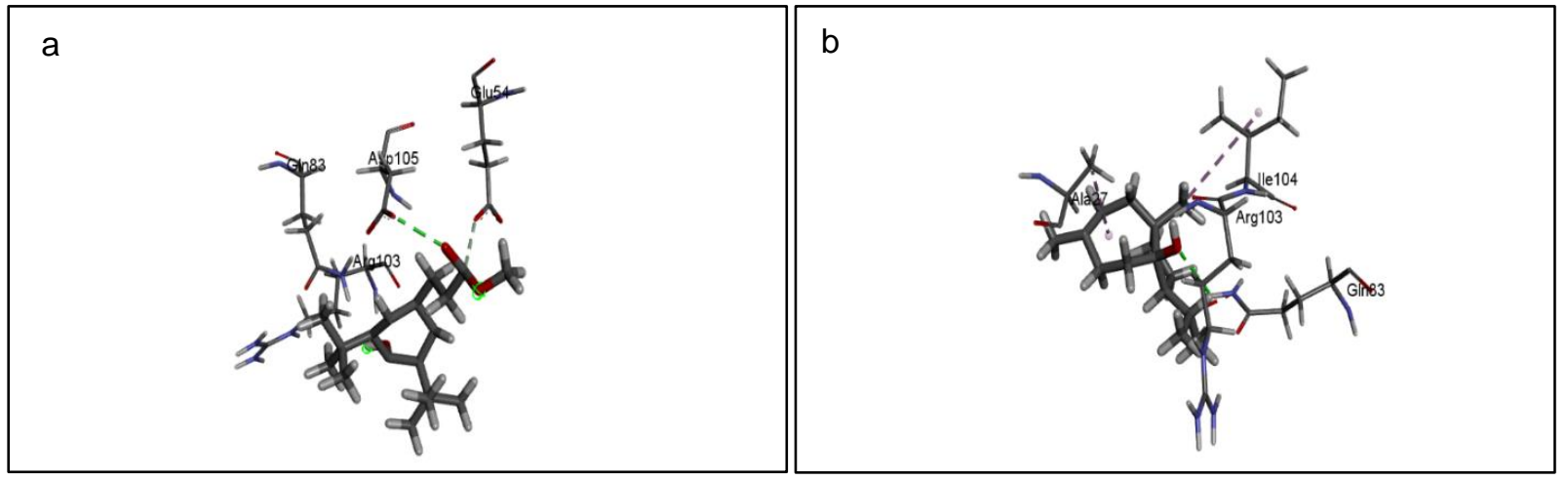

Figure 2. Docking interactions between Neurotrophin 3 (N3) and (a) Benzene propanoic acid, 3,5bis(1,1dimethylethyl)4hydroxy-, methyl ester (b) 3A(1H)-Azulenol,2,3,4,5,8,8A-hexahydro-6,8Adimethyl-3(1-M

\section{Neurotrophin 4 (N4)}

Neurotrophin 4 interacts with p75NTR through residues Gln83, Arg114, Tyr85, Asp32, Arg98, Arg34, Arg111, Asp75 and Arg107 ${ }^{36} .17$ phytochemicals interacted with the Neurotrophin 4. The interaction of the phytochemicals can be found in Table 3. 2,6,10-Trimethyl,14-ethylene-14-Pentadecne showed hydrophobic interactions with Val44, Ala47, Arg98, Leu52 and Trp110 with a docking score of 5,550 and an ACE of $213.87 \mathrm{kcal} / \mathrm{mol}$ (Figure 3a). 3,7,11,15-tetramethyl-2-Hexadecen-1-ol showed carbon hydrogen bonding with Gln54 and hydrophobic interactions with Arg98, Ala47, Val97, Val44, Trp110, Trp112 and Phe56 with a docking score of 5,432 and an ACE value of -286.35 kcal/mol (Figure 3b). 9-Octadecenoic acid (Z)- showed hydrogen bonding with Trp110 and hydrophobic interactions with Arg98, Ala47, Val97, Trp110 and Phe56 
with a docking score of 5,398 and an ACE of -265.53 kcal/mol (Figure 3c). Phytol showed hydrophobic interactions with Val44, Arg98, Ala47, Val97, Phe56 and Trp110 with a docking score of 5,550 and an ACE of $-312.72 \mathrm{kcal} / \mathrm{mol}$ (Figure 3d). Stigmasterol showed hydrophobic interactions with Trp110, Val44, Ala47, Arg98, Val97, Phe56, Trp110 and Trp112 with a docking score of 5,684 and an ACE of 409.31 kcal/mol (Figure 3e).
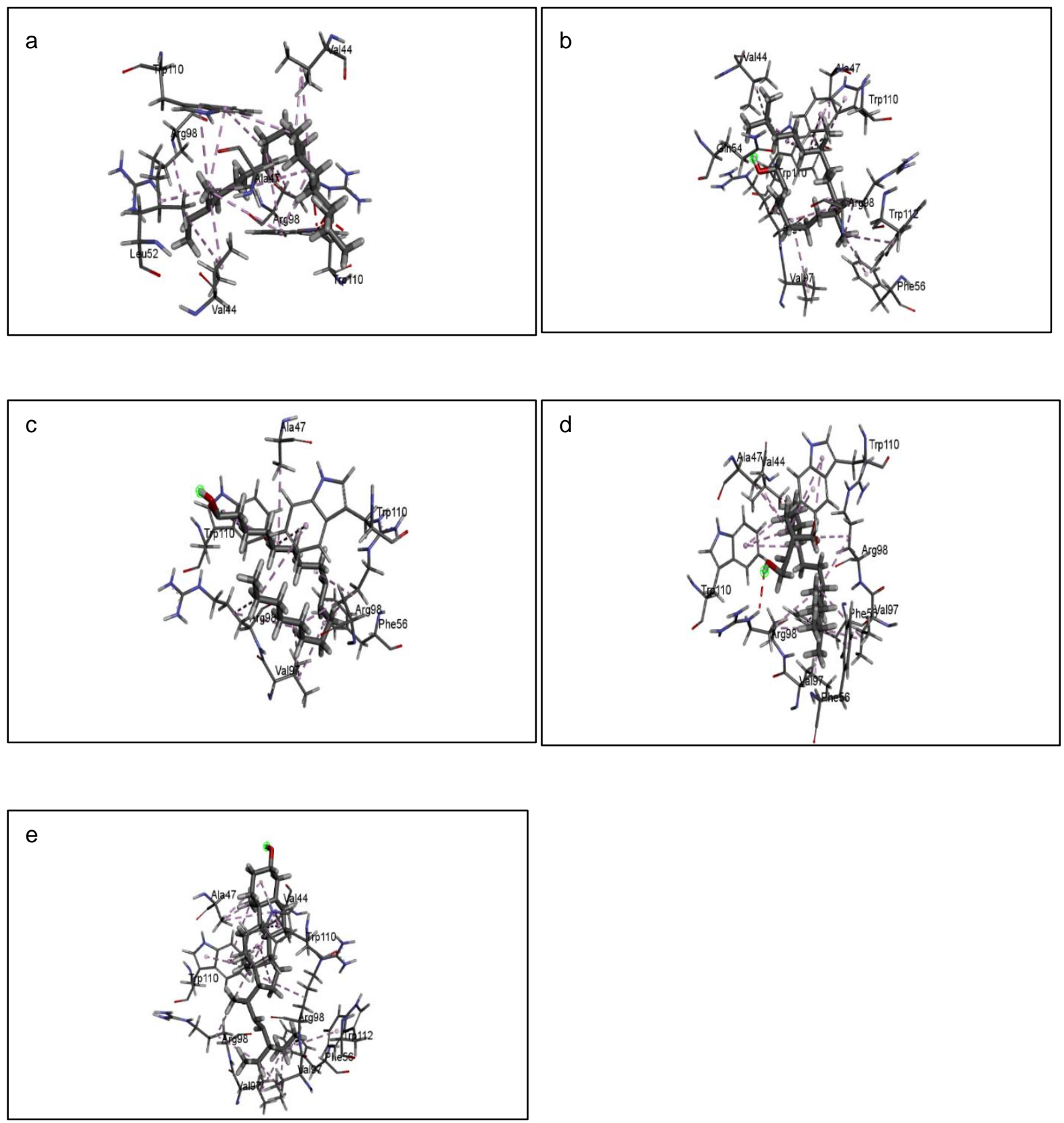
Figure 3. Docking interactions between Neurotrophin 4 and (a) 2,6,10-Trimethyl,14-ethylene-14Pentadecne (b) 3,7,11,15tetramethyl-2-Hexadecen-1-ol (c) 9-Octadecenoic acid (Z)- (d) Phytol (e) Stigmasterol

\section{Nerve Growth Factor (NGF)}

NGF interacts with p75NTR through residues Lys32, Lys34, Lys95, Arg103, His84, Arg100, Glu35, Lys88, Asp30, Asp93, Trp21 and Ile31 ${ }^{36} .11$ phytochemicals interacted with Nerve Growth Factor (NGF). The interaction between phytochemicals and the NGF is shown in Table 4. Heneicosane and Nonacosane showed better results as compared with other phytochemicals. Heneicosane showed hydrophobic interactions with Met37, Leu39, Met92 and Lys95 with a docking score of 5,136 and an ACE of -147.24 kcal/mol (Figure 4a). Nonacosane showed hydrophobic interactions with Lys32, Ala98, Ile31, Arg59, Trp21 and Phe54 with a docking score of 5,736 and an ACE value of $-171.43 \mathrm{kcal} / \mathrm{mol}$ (Figure 4b).

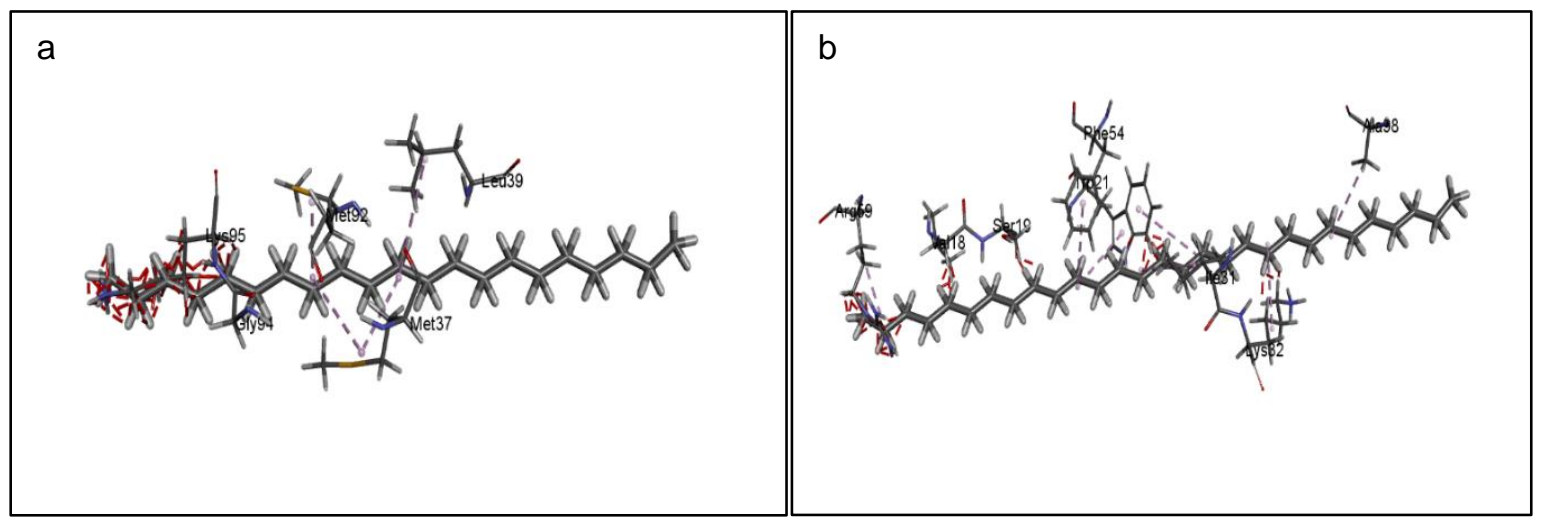

Figure 4. Docking interactions between Nerve Growth Factor (NGF) and (a) Heneicosane (b) Nonacosane

\section{Molecular Simulations}

Molecular simulations of the docking studies were performed for each Neurotrophin using CABS-Flex 2.0 online software (http://biocomp.chem.uw.edu.pl/CABSflex2/index). The corresponding RMSF values obtained were then plotted to see the individual fluctuations of the amino acid actively participating and interacting with the respective Neurotrophins.

\section{Brain Derived Neurotrophic Factor (BDNF)}


The molecular simulation studies of Vitamin E (Figure 5c) suggest that the curve almost fits closely to that of BDNF along with its natural ligand. Thus, from the curve it can be extrapolated that Vitamin E can possess the potential of imparting the anti-neurodegenerative activity to B. monnieri.

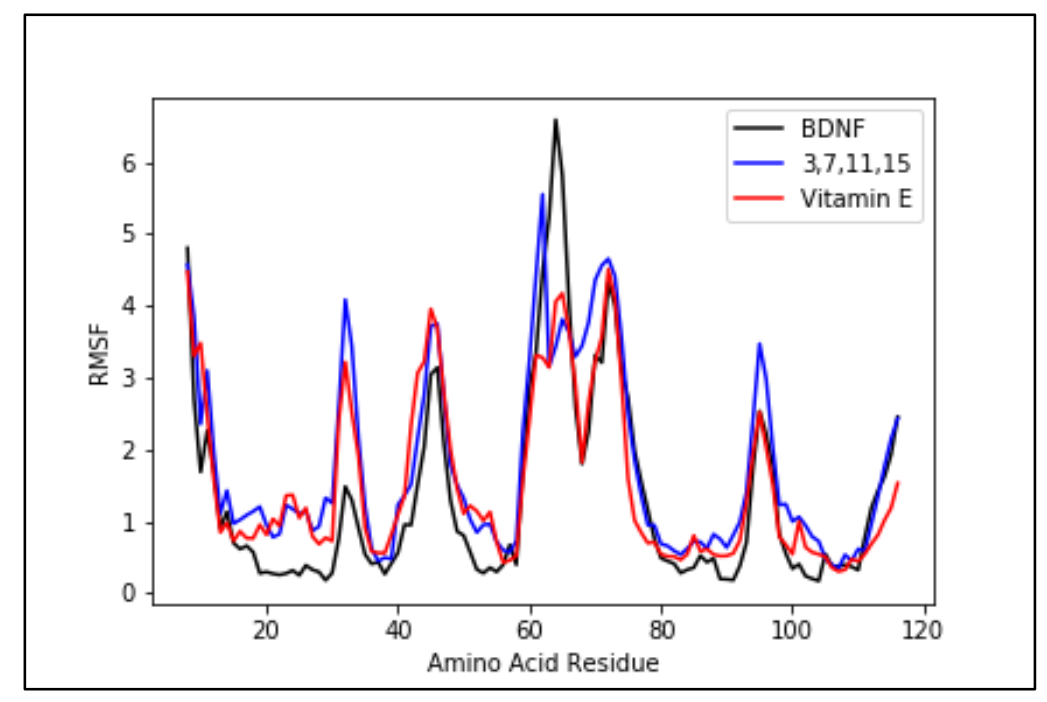

Figure 5. Molecular Simulation studies of BDNF docked with natural ligand, 3,7,11,15tetramethyl-2-Hexadecen-1-ol and Vitamin E

\section{Neurotrophin 3 (N3)}

Looking at the molecular simulation curve of $\mathrm{N} 3$ with the respective phytochemicals it can be seen that Benzene propanoic acid, 3,5-bis(1,1-dimethylethyl)-4hydroxy-, methyl ester (Figure 6b BPA) shows better results as compared with 3A(1H)-Azulenol,2,3,4,5,8,8A-hexahydro-6,8Adimethyl-3-(1-M (Figure 6c 3A(1H)). When the active amino acid is looked upon on the X-axis, it can be seen that the BPA curve for Gln 83 has a dip which goes beyond the curve of $\mathrm{N} 3$ suggesting that BPA is more stable than N3. A similar result can be seen for Arg103 as well. Comparing the molecular simulation results with the PatchDock score obtained it can be confirmed that BPA might also provide anti-depressant and anti-neurodegenerative activity to B. monnieri. 


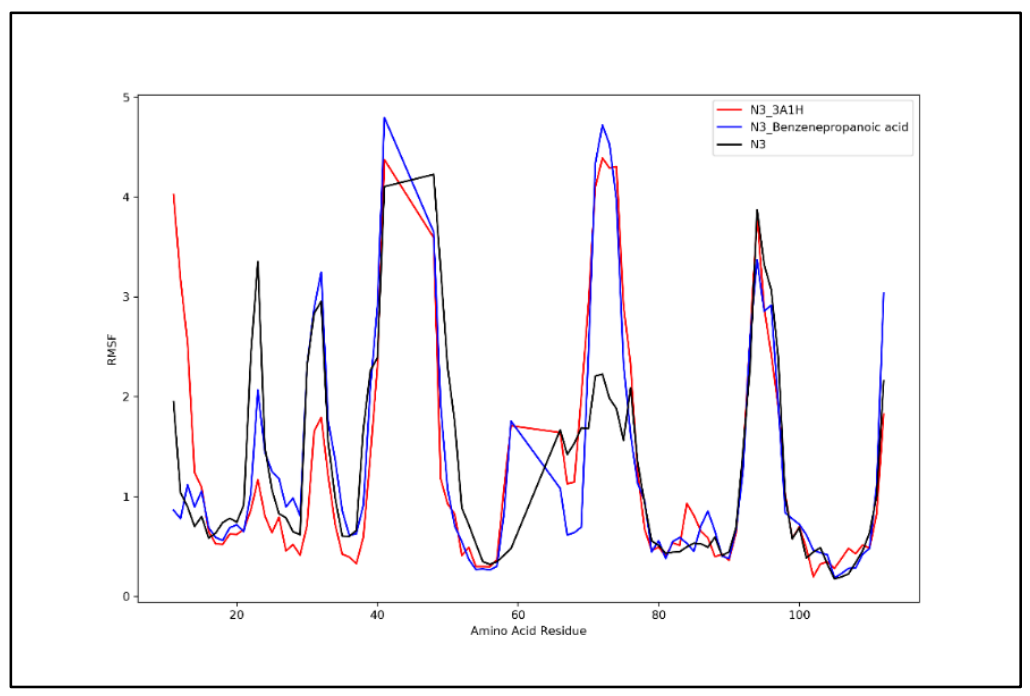

Figure 6. Molecular Simulation studies of N3 docked with natural ligand, Benzene propanoic acid, 3,5-bis(1,1dimethylethyl)-4hydroxy-, methyl ester and 3A(1H)-Azulenol,2,3,4,5,8,8Ahexahydro6,8Adimethyl-3-(1-M

\section{Neurotrophin 4 (N4)}

Molecular simulation studies of N4 with the respective phytochemicals suggest that Stigmasterol (Figure 7q) and Phytol (Figure 7o) shows better stability as compared to the binding of N4 with p $75^{\text {NTR }}$ (Figure 7p). Looking closely at the active amino acid residue Arg98, the RMSF curves for both Stigmasterol and Phytol are lower than N4. Also, comparing the corresponding results with the PatchDock score reveals that Stigmasterol and Phytol can also potentially provide B. monnieri with properties to improve cognition and learning.

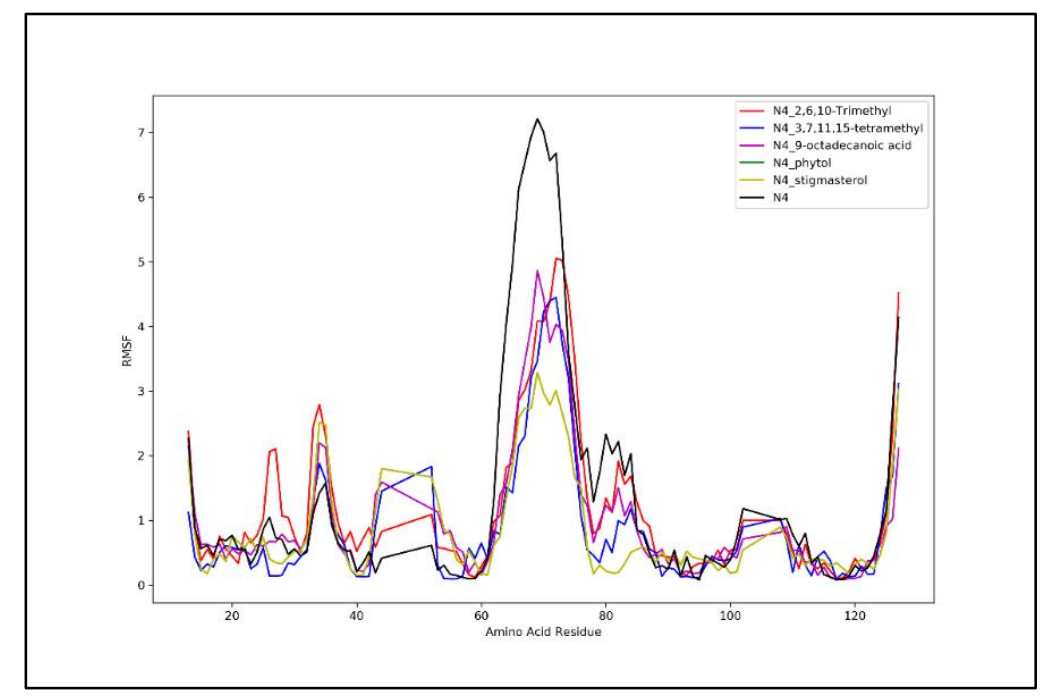


Figure 7. Molecular Simulation studies of N4 docked with 2,6,10-Trimethyl,14-ethylene-14-Pentadecne, 3,7,11,15tetramethyl-2Hexadecen-1-ol, 9Octadecenoic acid (Z)-, Phytol, Stigmasterol and Natural Ligand

\section{Nerve Growth Factor (NGF)}

The molecular simulation studies of NGF with the respective phytochemical shows that Heneicosane (Figure 8c) and Nonacosane (Figure 8f) showed better results as compared with other phytochemicals. Looking at the RMSF curve of Nonacosane (dashed yellow), it can be observed that the curve at amino acid residues Trp21, Ile31 and Lys32 is below the curve of NGF (Figure 81, black). This result suggests that the Nonacosane is more stable as compared to NGF. Also, the RMSF curve of Heneicosane (blue) at amino acid residue Lys95 is lower than the NGF curve suggesting a stable interaction. These results along with their PatchDock score suggests that Heneicosane and Nonacosane can also act as a potential source of providing B. monnieri the required antineurodegenerative activity.

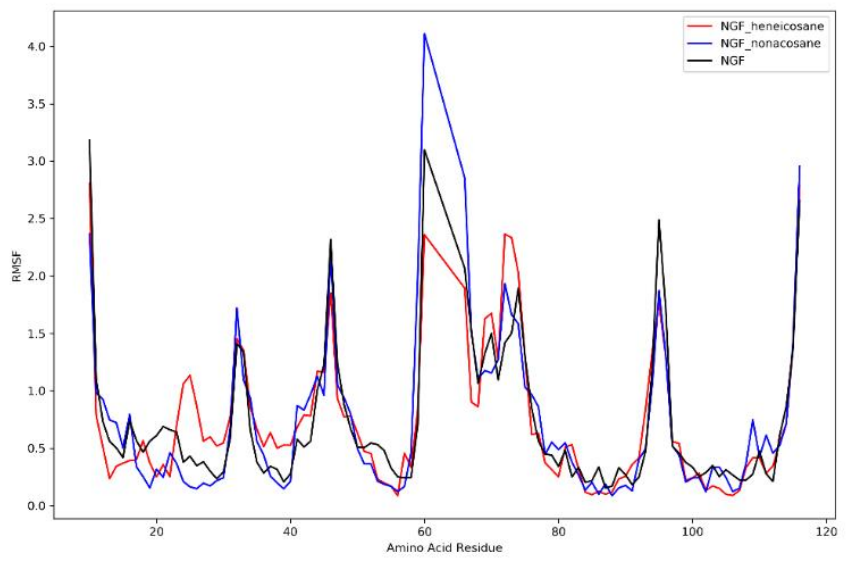

Figure 8. Molecular Simulation studies of NGF docked with Heneicosane, Nonacosane and Natural Ligand

\section{ADME Studies}

Drug likeness is the property of any compound to have the potential to act as a drug. Using the SWISSADME server, we analyzed the drug likeness ability of 3 commercial drugs and the 26 phytochemicals from B. monnieri (Table 1). Among the drugs commercially available for the treatment of MS, Cyclophosphamide shows the maximum drug likeness by following all the drug likeness rules (Lipinski's rule of five (RO5), Ghose filter rule, 
Veber rule, Egan rule and Muegge rule). The phytochemicals following all the rules of drug likeness were selected, as they correspond with Cyclophosphamide (Table 3).

The lipophilicity $(\log \mathrm{P})$ is an important factor to be considered while screening compounds based on their drug likeness ability. $\log \mathrm{P}$ values affect the rate of absorption of drug molecules in the body. The higher the value of $\log \mathrm{P}$ the lower absorption of the drug molecule. The three commercial drugs have qualified almost all the drug likeness parameters. In the phytochemicals of B. monnieri, 1,2-Benzenedicarboxylic acid, mono(2-ethylhexyl) ester (1,2-BDA), 2-Cyclohexen-1-one, 3-(3-hydroxybutyl)-2,4,4trimethyl (Cyclo-33) and Benzenepropanoic acid, 3,5-bis(1,1-dimethylethyl)-4hydroxy-, methyl ester (BPA) showed LogP values which were higher than Cyclophosphamide suggesting that their absorption is lower as compared to the drug. But, the LogP value of 2Cyclohexen-1-one, 4-hydroxy-3,5,5-trimethyl-4-(3oxo-1-butenyl)- (Cyclo-355) was in close proximity to that of the drug suggesting that the phytochemical has the potential to act as a natural drug molecule against MS.

The Synthetic Accessibility (SA) value of a compound suggests the ease with which the compound can be synthesized. SA value of 1 suggests that the compound can be easily synthesized whereas the value of 10 suggests that the synthesis can be challenging. The SA values of the phytochemicals were in the range of 2-3.5.

Table 3. ADME results for the commercial drugs and screened phytochemicals

\begin{tabular}{llllllll}
\hline & Cladribine & $\begin{array}{l}\text { Cyclophospha } \\
\text { mide }\end{array}$ & Mitoxantrone & 1,2-BDA & Cyclo-33 & Cyclo-355 & BPA \\
\hline Lipophilicity & & & & & & \\
ILOGP & 1.15 & 1.92 & 3.03 & 2.59 & 2.55 & 1.99 & 3.75 \\
XLOGP3 & 0.02 & 0.63 & 1 & 4 & 2.06 & 0.5 & 4.82 \\
WLOGP & -0.61 & 1.5 & -0.52 & 3.76 & 2.85 & 1.81 & 4.09 \\
MLOGP & -1.38 & 0.97 & -1.69 & 3.43 & 2.11 & 1.05 & 3.77 \\
\hline
\end{tabular}




\begin{tabular}{lllllllr}
\hline SILICOS-IT & -0.84 & 1.13 & 1.62 & 3.65 & 3.37 & 2.63 & 4.69 \\
Consensus & -0.33 & 1.23 & 0.69 & 3.49 & 2.59 & 1.59 & 4.32 \\
Log & & & & & &
\end{tabular}

\section{Water}

solubility

$\operatorname{LogS}(\mathrm{ESOL}) \quad-1.84$

$-1.53$

$-2.71$

$-3.71$

$-2.24$

$-1.4$

$-4.5$

Class

Very soluble

Very soluble

Soluble

Soluble

Soluble

Very soluble

Moderately

$\operatorname{LogS}$ (Ali)

$-2.08$

$-1.28$

$-4.02$

$-5.04$

$-2.47$

$-1.21$

$-5.53$

Class

Soluble

Very Soluble

Moderately

Moderately

Soluble

Very soluble

Moderately

Soluble

Soluble

Soluble

$\log S$

$-1.01$

$-2.71$

$-6.27$

$-4.3$

$-3.23$

$-2.19$

$-5.12$

(SILICOS-IT)

Class

$$
\text { Soluble }
$$

Soluble

Poorly

Moderately

Soluble

Soluble

Moderately

soluble

Soluble

Soluble

\section{Pharmacokine}

tics

GI

High

High

Low

High

High

High

High

Absorption

BBB

No

Yes

No

Yes

Yes

Yes

Yes

Permeant

P-gp

No

No

Yes

No

No

No

No

Substrate 


\begin{tabular}{|c|c|c|c|c|c|c|c|}
\hline CYP1A2 & No & No & No & No & No & No & No \\
\hline \multicolumn{8}{|l|}{ Inhibitor } \\
\hline CYP2C9 & No & No & No & No & No & No & No \\
\hline \multicolumn{8}{|l|}{ Inhibitor } \\
\hline CYP2C19 & No & No & No & No & No & No & No \\
\hline \multicolumn{8}{|l|}{ Inhibitor } \\
\hline CYP2D6 & No & No & No & No & No & No & Yes \\
\hline \multicolumn{8}{|l|}{ Inhibitor } \\
\hline CYP3A4 & No & No & No & No & No & No & No \\
\hline \multicolumn{8}{|l|}{ Inhibitor } \\
\hline Log Kp (Skin & -8.03 & -7.45 & -8.3 & -5.61 & -6.12 & -7.3 & -4.66 \\
\hline \multicolumn{8}{|l|}{ Permeation) } \\
\hline \multicolumn{8}{|l|}{ Drug } \\
\hline \multicolumn{8}{|l|}{ likeness } \\
\hline Lipinski & Yes & Yes & Yes & Yes & Yes & Yes & Yes \\
\hline Ghose & No & Yes & No & Yes & Yes & Yes & Yes \\
\hline Veber & Yes & Yes & No & Yes & Yes & Yes & Yes \\
\hline Egan & Yes & Yes & No & Yes & Yes & Yes & Yes \\
\hline Muegge & Yes & Yes & No & Yes & Yes & Yes & Yes \\
\hline Bioavailabilit & 0.55 & 0.55 & 0.55 & 0.85 & 0.55 & 0.55 & 0.55 \\
\hline
\end{tabular}

\section{Medicinal}

Chemistry 


\begin{tabular}{|c|c|c|c|c|c|c|c|}
\hline Pains & 0 alert & 0 alert & 2 alerts & 0 alert & 0 alert & 0 alert & 0 alert \\
\hline Brenk & 0 alert & 2 alerts & 1 alert & 0 alert & 0 alert & 1 alert & 0 alert \\
\hline Leadlikeness & Yes & Yes & No & No & No & No & No \\
\hline Synthetic & 3.65 & 3.7 & 3.61 & 2.95 & 3.4 & 3.46 & 2.13 \\
\hline Accessibility & & & & & & & \\
\hline
\end{tabular}

1,2-BDA $\rightarrow$ 1,2-Benzenedicarboxylic acid, mono(2-ethylhexyl) ester

Cyclo-33 $\rightarrow$ 2-Cyclohexen-1-one, 3-(3-hydroxybutyl)-2,4,4trimethyl-

Cyclo-355 $\rightarrow$ 2-Cyclohexen-1-one, 4-hydroxy-3,5,5-trimethyl-4-(3oxo-1-butenyl)-

BPA $\rightarrow$ Benzenepropanoic acid, 3,5-bis(1,1-dimethylethyl)-4hydroxy-, methyl ester

\section{DISCUSSION}

Neurodevelopmental disorders are an important aspect to be considered. The disorders affect various parts of brain resulting in changes associated with memory, locomotion, behavior, emotions. Neurocognition and attention is an important aspect of humans to survive on a day-to-day basis. Thus, it it is of utmost importance to devise drugs that can target the neurocognitive and neurodevelopmental disorders in order to assist the patient with a better lifestyle. Synthetic drugs are not able to cure the disorders with a hundred percent certainty. Also, the risk of side effect is always associated with commercial drugs that are synthesized chemically. Bacopa monnieri has garnered much attention in recent years for its ability to enhance the neurocognitive and attention properties of human brain ${ }^{75}$. This study focuses on finding the major phytochemical that imparts $B$. monnieri with neurocognitive properties. Molecular docking studies suggest that, the medicinal property of B. monnieri is due to the combined effect of the phytochemicals of the plant rather than a single phytochemical. Further investigations with molecular dynamic simulations show that there is a stable binding of the phytochemicals of B. monnieri with Neurotrophins. The RMSF fluctuations of the phytochemicals were better than the commercial drugs available, which makes it a better drug candidate. Based on these study, four major phytochemicals were 
screened for ADME studies to find their characteristic likeness with that of the commercial drugs available. All the four phytochemicals followed the Drug likeness rules (Lipinski's, Ghose, Veber, Egan, Meugge) and the bioavailability score of these phytochemicals were same as that of the commercial drug which further suggests their potential to act as a drug candidate. Future work with animal models can provide us with experimental results that will further support the current study and take us a step closer for the development of neurocognitive and neuroprotective drugs.

\section{CONCLUSION}

Bacopa monnieri has been extensively used to treat the neurological disorders. Its ayurvedic roots make it a plant of medicinal purpose. It is associated with improving the brain function including intelligence and $\operatorname{cognition}^{61}$. B. monnieri extract when used to treat the animal model of Alzheimer's (C57/B16 mice) showed a neuroprotective mechanism and it restricts the $\beta$-amyloid formation ${ }^{74}$. These results suggest that B. monnieri can act as a potential drug candidate against several other neurodegenerative disorders. Yet, it is unclear as to how B. monnieri actually causes these activities. The current work was done with aim of understanding the major involvement of phytochemical that proves B. monnieri to be useful in cases of neurodegenerative disorders. This study suggests that, there is no single phytochemical responsible for the B. monnieri activity. It is the amalgamation of majority of the natural phytochemicals of B. monnieri that makes it a medicinal plant that can be employed for various neurological disorders. Still, experiments will be required to find the molecular mechanism behind its action and to find out how the plant imparts its effect. Our work is a step towards unraveling the mystery behind the medicinal property of B. monnieri. The computational studies conducted in this work reveals the innate medicinal nature of the phytochemicals and their potential to act as a drug candidate.

\section{CONFLICT OF INTEREST}

The authors declare no conflict of interest. 


\section{FUNDING}

Not Applicable

\section{REFERENCES}

[1] Armando DV, Antonio G, Giovanni F, Maurizio I, Maria R, Andrea G, et al. Autoimmunity

Reviews Parkinson's disease : Autoimmunity and neuroin fl ammation. 2016;

[2] Tabrizi SJ, Square Q. Huntington's disease: a clinical review.

[3] Wan Y, Al-ouran R, Mangleburg CG, Shulman JM, Mangravite LM, Logsdon BA. Resource MetaAnalysis of the Alzheimer' s Disease Human Brain Transcriptome and Functional Dissection in Mouse Models Meta-Analysis of the Alzheimer's Disease Human Brain Transcriptome and Functional Dissection in Mouse Models. 2020;

[4] Radunovic A, Annane D, Mk R, Brassington R, Mustfa N. Mechanical ventilation for amyotrophic lateral sclerosis / motor neuron disease ( Review ) SUMMARY OF FINDINGS FOR THE MAIN COMPARISON. 2017;(10).

[5] Burrell JR, Halliday GM, Kril JJ, Ittner LM, Götz J, Kiernan MC, et al. The frontotemporal dementia-motor neuron disease continuum. 2016;6736(15).

[6] Paulson HL, Shakkottai VG, Clark HB, Orr HT. Polyglutamine spinocerebellar ataxias — from genes to potential treatments. Nat Publ Gr [Internet]. 2017;18(10):613-26. Available from: http://dx.doi.org/10.1038/nrn.2017.92

[7] Yang C, Lo C, Wu M. Ischemic stroke in a young patient with Fahr' s disease : a case report. BMC Neurol [Internet]. 2016;1-5. Available from: http://dx.doi.org/10.1186/s12883-016-0557-8 
[8] Marine A, De B, Abbas AR, Jouan BF, Gysel CD Van, Chauveheid MP, et al. ORIGINAL Systemic infl ammatory disorders in patients admitted. 2018;

[9] Tyler K.L. Acute Viral Encephalitis. 2018;557-66.

[10] Berkowitz BAL. Tetanus, Botulism, and Diphtheria. 2018;1459-88.

[11] Yuen AWC, Keezer MR, Sander JW. Epilepsy \& Behavior Epilepsy is a neurological and a systemic disorder. Epilepsy Behav [Internet]. 2018;78:57-61. Available from: https://doi.org/10.1016/j.yebeh.2017.10.010

[12] Mohamed K, Koriem M. SC [Internet]. Asian Pacific Journal of Tropical Biomedicine. Elsevier Ltd; 2016. Available from: http://dx.doi.org/10.1016/j.apjtb.2016.03.009

[13] Vázquez-costa JF, Arlandis S, Hervas D, Martínez-cuenca E, Cardona F, Pérez-tur J, et al. Clinical profile of motor neuron disease patients with lower urinary tract symptoms and neurogenic bladder. $\mathbf{J}$ Neurol Sci [Internet]. 2017; Available from: http://dx.doi.org/10.1016/j.jns.2017.04.053

[14] Weldon F.K, El-Koussy M, Jung S, Jossen M, Klinger-Gratz P.P, Wiest R. Cerebellar Hypoperfusion in Migraine Attack: Incidence and Significance. 2018;(Ccd):1-6.

[15] Kahriman A. Migraine and Tension-Type Headache. 2018;608-18.

[16] Orhan E.K. Current Approach to Medication Overuse Headache. 2019;233-4.

[17] Ostrom QT, Wright CH, Barnholtz-sloan JS. Brain metastases : epidemiology [Internet]. 1st ed. Vol. 149, Metastatic Disease of the Nervous System. Elsevier B.V.; 2018. 27-42 p. Available from: http://dx.doi.org/10.1016/B978-0-12-811161-1.00002-5 
[18] Gourie-Devi M. Epidemiology of neurological disorders in India : Review of background, prevalence and incidence of epilepsy, stroke, Parkinson' s disease and tremors. 2014;62(6).

[19] Hempstead BL. Dissecting the Diverse Actions of Pro- and Mature Neurotrophins. 2006;19-24.

[20] Leake PA, Akil O, Lang H. Neurotrophin gene therapy to promote survival of spiral ganglion neurons after deafness. Hear Res [Internet]. 2020;(xxxx):107955. Available from: https://doi.org/10.1016/j.heares.2020.107955

[21] Sahu MP, Pazos-boub Y. Neurotrophin receptor Ntrk2b function in the maintenance of dopamine and serotonin neurons in zebrafish. 2019;(June 2018):1-13.

[22] Reichardt LF, Reichardt LF. Neurotrophin-regulated signalling pathways Neurotrophin-regulated signalling pathways. 2006;(September).

[23] Autry AE, Bambah-mukku D. The role of brain-derived neurotrophic factor in neural circuit development and function [Internet]. Vol. 3, Synapse Development and Maturation. Elsevier Inc.; 2020. 443-466 p. Available from: http://dx.doi.org/10.1016/B978-0-12-823672-7.00020-X

[24] Vilar M, Mira H. Regulation of Neurogenesis by Neurotrophins during Adulthood : Expected and Unexpected Roles. 2016;10(February):1-9.

[25] Sahay A, Kale A, Joshi S. Neuropeptides Role of neurotrophins in pregnancy and o ff spring brain development. Neuropeptides [Internet]. 2020;83(July):102075. Available from: https://doi.org/10.1016/j.npep.2020.102075 
[26] Konar A, Shah N, Singh R, Saxena N, Kaul SC, Wadhwa R. Protective Role of Ashwagandha Leaf Extract and Its Component Withanone on Scopolamine-Induced Changes in the Brain and BrainDerived Cells. 2011;6(11).

[27] Tseng P, Chen Y, Tu K, Wang H, Chung W, Wu C, et al. State-dependent increase in the levels of neurotrophin-3 and neurotrophin-4 / 5 in patients with bipolar disorder : A meta-analysis. J Psychiatr Res [Internet]. 2016;79:86-92. Available from: http://dx.doi.org/10.1016/j.jpsychires.2016.05.009

[28] Hyun K, Ah M, Moon E, Yeou S, Zin S, Won M, et al. Bioorganic \& Medicinal Chemistry Letters Furostanol saponins from the rhizomes of Dioscorea japonica and their effects on NGF induction. Bioorg Med Chem Lett [Internet]. 2011;21(7):2075-8. Available from: http://dx.doi.org/10.1016/j.bmcl.2011.02.003

[29] Vivar-cortés VGGFMTCI, Hernández-echeagaray E. 3 restores synaptic plasticity in the striatum of a mouse model of Huntington's disease. 2018;(November 2017):1-11.

[30] Allen SJ, Dawbarn D. Clinical relevance of the neurotrophins and their receptors. 2006;191:17591.

[31] Cho T, Ryu JK, Taghibiglou C, Ge Y, Chan AW, Liu L, et al. Long-Term Potentiation Promotes Proliferation / Survival and Neuronal Differentiation of Neural Stem / Progenitor Cells. 2013;8(10).

[32] Fitzsimons CP, Bodegraven E Van, Schouten M, Lardenoije R, Kompotis K, Kenis G, et al. Epigenetic regulation of adult neural stem cells : implications for Alzheimer's disease. 2014;1-21.

[33] Simmons DA. Modulating Neurotrophin Receptor Signaling as a Therapeutic Strategy for Huntington's Disease. 2017;6:303-25. 
[34] Meldolesi J. Neurotrophin Receptors in the Pathogenesis , Diagnosis and Therapy of Neurodegenerative Diseases . Pharmacol Res [Internet]. 2017; Available from: http://dx.doi.org/10.1016/j.phrs.2017.04.024

[35] Jiang Y, Fay JM, Poon C, Vinod N, Zhao Y, Bullock K, et al. Nanoformulation of Brain-Derived Neurotrophic Factor with Target Receptor-Triggered-Release in the Central Nervous System. 2018;1703982:1-11.

[36] Shamovsky IL, Ross GM, Riopelle RJ, Donald F. Chapter 15 MOLECULAR MODELING OF THE INTERACTION OF NEUROTROPHINS WITH THE COMMON NEUROTROPHIN RECEPTOR.

[37] Drinkwater CC, Suter U, Angst C, Shooter EM, Drinkwater CC, Suter U, et al. Mutation of Tryptophan-21 in Mouse Nerve Growth Factor ( NGF ) Affects Binding to the Fast NGF Receptor but not Induction of Neurites on PC12 Cells Mutation of tryptophan-21 in mouse nerve growth factor ( NGF ) affects binding to the fast NGF receptor but not induction of neurites on PC12 cells. 2020;246(1317):307-13.

[38] Duraes F. Old Drugs as New Treatments for Neurodegenerative Diseases. 2018;1-21.

[39] Hartung H, Gonsette R, König N, Kwiecinski H, Guseo A, Morrissey SP, et al. Mitoxantrone in progressive multiple sclerosis : a placebo- controlled, double-blind, randomised, multicentre trial. 2018;360:2018-25.

[40] Awad A, Stu O. Cyclophosphamide in multiple sclerosis : scientific rationale, history and novel treatment paradigms. 2009;357-68. 
[41] Holmøy T, Torkildsen $\emptyset$, Myhr KM. Expert Opinion on Pharmacotherapy An update on cladribine for relapsing-remitting multiple sclerosis. 2017;6566(September).

[42] Arun T, Tomassini V, Sbardella E, Ruiter MB De, Matthews L, Leite MI, et al. Targeting ASIC1 in primary progressive multiple sclerosis : evidence of neuroprotection with amiloride. 2013;106-15.

[43] Barkhof F, Hulsr H.E, Drulovic J, Uirdehaag B.M.J, Marsuda K, Landin R. Ibudilast in relapsingremitting multiple sclerosis. 2010;1033-40.

[44] Patti F, Fermo S Lo. Lights and Shadows of Cyclophosphamide in the Treatment of Multiple Sclerosis. 2011;2011.

[45] Lörinczy D. Cyclophosphamide treatment evoked side effects on skeletal muscle monitored by DSC. J Therm Anal Calorim [Internet]. 2020;(0123456789):2-6. Available from: https://doi.org/10.1007/s10973-020-09388-2

[46] Kim YC. Neuroprotective Phenolics in Medicinal Plants. 2010;33(10):1611-32.

[47] Calabrese V, Cornelius ÆC, Mancuso ÆC, Pennisi ÆG, Calafato S, Bellia ÆF, et al. Cellular Stress Response : A Novel Target for Chemoprevention and Nutritional Neuroprotection in Aging, Neurodegenerative Disorders and Longevity. 2008;2444-71.

[48] Mani V, Ramasamy K, Ahmad A, Parle M, Adnan S, Shah A, et al. Protective effects of total alkaloidal extract from Murraya koenigii leaves on experimentally induced dementia. FOOD Chem Toxicol [Internet]. 2012;50(3-4):1036-44. Available from: http://dx.doi.org/10.1016/j.fct.2011.11.037

[49] Kim, D. H., Kim, S., Jung, W. Y., Park, S. J., Park, D. H., Kim, J. M., Cheong, J. H., \& Ryu, J. H. (2009). The neuroprotective effects of the seeds of Cassia obtusifolia on transient cerebral global 
ischemia in mice. Food and Chemical Toxicology, 47(7), 1473-1479.

https://doi.org/10.1016/j.fct.2009.03.028

[50] Ban JY, Thuy T, Ee HL, Ho OC, U HSJ, Im YK. Neuroprotective Properties of Gallic Acid from Sanguisorbae Radix on Amyloid b Protein ( 25 - 35 ) -Induced Toxicity in Cultured Rat Cortical. 2008;31(January):149-53.

[51] Gachkar L, Yadegari D, Bagher M, Taghizadeh M. Food Chemistry Chemical and biological characteristics of Cuminum cyminum and Rosmarinus officinalis essential oils. 2007;102:898-904.

[52] Hao BWÆ, Wei WÆZ, Lu YSÆ, Chen ZÆH. Efficacy and safety of natural acetylcholinesterase inhibitor huperzine A in the treatment of Alzheimer' s disease : an updated meta-analysis. 2009;45765.

[53] Fujiwara H, Tabuchi M, Yamaguchi T, Iwasaki K, Furukawa K, Sekiguchi K, et al. A traditional medicinal herb Paeonia suffruticosa and its active constituent 1,2,3,4,6-penta- $O$-gallolyl- $\beta$-Dglucopyranose have potent anti-aggregation effects on Alzheimer's amyloid $\beta$ proteins in vitro and in vivo. Neurochemistry JOF. 2009;1648-57.

[54] Tildesley NTJ, Kennedy DO, Perry EK, Ballard CG, Savelev S, Wesnes KA, et al. Salvia lavandulaefolia ( Spanish Sage ) enhances memory in healthy young volunteers. 2003;75:669-74.

[55] Soh Y, Im JK, Ohn WS, Ee RL, Yeou S, Im K. Protective Effects of Quinic Acid Derivatives on Tetrahydropapaveroline- Induced Cell Death in C6 Glioma Cells. 2003;26(June):803-7.

[56] Liu M, Chen F, Sha L, Wang S, Tao L. ( - ) -Epigallocatechin-3-Gallate Ameliorates Learning and Memory Deficits by Adjusting the Balance of TrkA / p75 NTR Signaling in APP / PS1 Transgenic Mice. 2013;2. 
[57] Liao K, Wu M, Chen P, Huang S, Chiu S, Ho C, et al. Curcuminoids Promote Neurite Outgrowth in PC12 Cells through MAPK/ERK- and PKC-Dependent Pathways. 2012;60,433-443

[58] Zhang C, Tian X, Luo Y, Meng X. Ginkgolide B attenuates ethanol-induced neurotoxicity through regulating NADPH oxidases. Toxicology [Internet]. 2011;287(1-3):124-30. Available from: http://dx.doi.org/10.1016/j.tox.2011.06.006

[59] Hur J, Lee P, Moon E, Kang I, Kim S, Sook M, et al. Neurite outgrowth induced by spicatoside A, a steroidal saponin, via the tyrosine kinase A receptor pathway. Eur J Pharmacol [Internet]. 2009;620(1-3):9-15. Available from: http://dx.doi.org/10.1016/j.ejphar.2009.08.016

[60] Kumar M, Prabhakar S, Anand A. Pharmacology , Biochemistry and Behavior Neuroprotective effect of Bacopa monniera on ischemia induced brain injury. Pharmacol Biochem Behav [Internet]. 2010;97(2):192-7. Available from: http://dx.doi.org/10.1016/j.pbb.2010.07.017

[61] Sukumaran NP, Amalraj A, Gopi S. Complementary Therapies in Medicine Neuropharmacological and cognitive e ff ects of Bacopa monnieri ( L .) Wettst - A review on its mechanistic aspects. Complement Ther Med [Internet]. 2019;44(February):68-82. Available from: https://doi.org/10.1016/j.ctim.2019.03.016

[62] Russo A, Borrelli F. Bacopa monniera , a reputed nootropic plant : an overview. 2005;12:305-17.

[63] Stough C, Scholey A, Cropley V, Wesnes K, Zangara A, Pase M, et al. Examining the Cognitive Effects of a Special Extract of Bacopa Monniera ( CDRI 08 : KeenMind ): A Review of Ten Years of Research at Swinburne University. 2013;16(2):254-8.

[64] Bhattacharya S, Subramanian M, Roychowdhury S, Bauri AK, Kamat JP, Chattopadhyay S, et al. Radioprotective Property of the Ethanolic Extract of Piper betel Leaf. 2005;46(2):165-71. 
[65] Shinomol GK, Babu R, Muralidhara MMSB. Bacopa monnieri Extract Offsets Rotenone-Induced Cytotoxicity in Dopaminergic Cells and Oxidative Impairments in Mice Brain. 2012;455-65.

[66] Uabundit N, Wattanathorn J, Mucimapura S, Ingkaninan K. Cognitive enhancement and neuroprotective effects of Bacopa monnieri in Alzheimer's disease model. 2010;127:26-31.

[67] Lal UR, Lal S. Bioactive Molecules from Indian Medicinal Plants as Possible Candidates for the Management of Neurodegenerative Disorders. :0-21.

[68] Kim S, Chen J, Cheng T, Gindulyte A, He J, He S, et al. PubChem 2019 update : improved access to chemical data. 2019;47(October 2018):1102-9.

[69] Boyle NMO, Banck M, James CA, Morley C, Vandermeersch T, Hutchison GR. Open Babel : An open chemical toolbox. 2011;1-14.

[70] ChemOffice, 7.0.1. 2002. CambridgeSoft, Corporation, Cambridge, MA.

[71] UCSF Chimera--a visualization system for exploratory research and analysis. Pettersen EF, Goddard TD, Huang CC, Couch GS, Greenblatt DM, Meng EC, Ferrin TE. J Comput Chem. 2004 Oct;25(13):1605-12.

[72] BIOVIA, Dassault Systèmes, Discovery Studio 2020 Client, San Diego: Dassault Systèmes

[73] Daina A, Michielin O, Zoete V. SwissADME : a free web tool to evaluate pharmacokinetics , drug- likeness and medicinal chemistry friendliness of small molecules. Nat Publ Gr [Internet]. 2017;(March):1-13. Available from: http://dx.doi.org/10.1038/srep42717

[74] Dhanasekaran M, Tharakan B, Holcomb LA, Hitt AR, Young KA, Manyam B V. Neuroprotective Mechanisms of Ayurvedic Antidementia Botanical Bacopa monniera. 2007;969(June):965-9. 
bioRxiv preprint doi: https://doi.org/10.1101/2021.01.20.427542; this version posted January 21, 2021. The copyright holder for this preprint (which was not certified by peer review) is the author/funder. All rights reserved. No reuse allowed without permission.

[75] Chaudhari KS, Tiwari R, Tiwari RR. Neurocognitive Effect of Nootropic Drug Brahmi ( Bacopa monnieri ) in Alzheimer's ' Disease. 2017;111-22. 